\title{
Mucormycosis Surge with the Second Wave of COVID-19 in India
}

\author{
K Upasana ${ }^{1}$, Neha Rastogi ${ }^{1}$, Dhwanee Thakkar ${ }^{1}$, Anjali Yadav ${ }^{1}$, Sunisha Arora ${ }^{1}$, and Satya \\ Yadav $^{1}$ \\ ${ }^{1}$ Affiliation not available
}

May 24, 2021

K Upasana, Neha Rastogi, Dhwanee Thakkar, Anjali Yadav, Sunisha Arora, Satya Prakash Yadav

Pediatric Hematology Oncology and Bone Marrow Transplant Unit, Cancer Institute, Medanta The Medicity Hospital, Gurgaon, Haryana, India.

Correspondence : Dr Satya P Yadav, Pediatric Hematology Oncology \& BMT Unit, Cancer Institute, Medanta -The Medicity, Gurgaon, Haryana, India 122001.

Email:satya_1026@hotmail.com, Fax: +911244962222

Total Pages - 7

Abstract (word count) - N/A

Table - 0

Figure - 0

Text (word count) -480

Running title - Mucormycosis post covid19

Key words - Mucormycosis; Covid-19; India

\section{To the editor:}

In recent times, we have seen a steep rise in cases of invasive mucormycosis infection in patients of COVID19 (Coronavirus infection disease 2019) in India. We reviewed literature to find plausible cause of this association. Considering the pathogenesis, fungal spores need to evade the innate immune system and germinate, leading to angioinvasion and tissue destruction. Literature states that mucorales are able to downregulate several host defense mechanisms and attach to the endothelium via specific receptors, GRP78 facilitating their endocytosis and angioinvasion. Factors such as hyperglycemia, elevated iron concentrations, and acidosis have been shown to contribute to the pathogenesis in experimental setup and animal models. The antifungal properties of platelets and natural killer cells have been demonstrated (1). But reasons for mucormycosis happening post covid19 are still not clear.

Review of literature published till April of 2021 revealed 68 cases of mucormycosis in patients of COVID19. Rhino-ocular-cerebral infections comprised the majority (60/68). Less common sites included pulmonary mucormycosis $(5 / 68)$, and 1case each of cutaneous, gastrointestinal tract and fulminant mucormycosis. India accounted for $75 \%$ of published cases (51/68) (2-10), followed by United States of America (9/68) (11-18), Iran (4/68) (19-21) and 1 case each from Brazil (22), Mexico (23), Italy (24) and Austria (25). Most patients suffering this complication of mucormycosis had some underlying co-morbidity mainly diabetes mellitus, but infections in immunocompetent persons have also been seen. 
The second wave of COVID-19 pandemic in India has seen a sudden surge in cases of mucormycosis and associated complications of vision loss, brain abscess and stroke. Both morbidity and mortality are on a rise post this fungal infection. Maharashtra, a state in India with a population of approximate 114 million has documented 1500 cases of mucormycosis post covid-19 with 52 death in last 1-month (26). As per one report, India has a total of 8,848 mucormycosis cases post covid19 after many states have made it's a notifiable disease (27).

Why such a steep rise in cases of mucormycosis post second wave of covid-19? In second wave India has had too many cases of covid-19 which hospital system could handle so many patients were prescribed steroids early and given longer in the hope of avoiding need for oxygen and hospital admission. India is the diabetes capital of India. Severe Covid-19 causes activation of immune system which raises ferritin. Covid-19 is frequently associated with lymphopenia. So, a combination of steroids, diabetes, high ferritin and lymphopenia might be contributing to this sudden and steep rise $(1,3)$. Another factor could be that new strain of SARS-COV-2, B.1.617 reported in this second wave in India is more infectious so more cases and also it is somehow promoting entry of mucorales into the patients. With such rapid rise in cases there is an urgent need to identify patients at risk of this infection and start urgent treatment to save lives and avoid debilitating complications. Mucormycosis post covid19 in India has reached epidemic proportions and more research is needed about this association.

\section{References}

1. Petrikkos G, Tsioutis C. Recent Advances in the Pathogenesis of Mucormycoses. Clinical Therapeutics. 2018 Jun;40(6):894-902.

2. Sarkar S, Gokhale T, Choudhury SS, Deb AK. COVID-19 and orbital mucormycosis. Indian J Ophthalmol. 2021 Apr;69(4):1002-4.

3. Garg D, Muthu V, Sehgal IS, Ramachandran R, Kaur H, Bhalla A, Puri GD, Chakrabarti A, Agarwal R. Coronavirus Disease (Covid-19) Associated Mucormycosis (CAM): Case Report and Systematic Review of Literature. Mycopathologia. 2021 May;186(2):289-298. doi: 10.1007/s11046-021-00528-2. Epub 2021 Feb 5.

4. Verma DK, Bali RK. COVID-19 and Mucormycosis of the Craniofacial skeleton: Causal, Contributory or Coincidental? J Maxillofac Oral Surg. 2021 Jun;20(2):165-6.

5. Sen M, Honavar SG, Sharma N, Sachdev MS. COVID-19 and Eye: A Review of Ophthalmic Manifestations of COVID-19. Indian Journal of Ophthalmology [Internet]. 2021;69(3). Available from: https://journals.lww.com/ijo/Fulltext/2021/03000/COVID_19_and_Eye__A_Review_of_Ophthalmic.8.aspx

6. Sen M, Lahane S, Lahane TP, Parekh R, Honavar SG. Mucor in a Viral Land: A Tale of Two Pathogens. Indian J Ophthalmol. 2021 Feb;69(2):244-52.

7. Maini A, Tomar G, Khanna D, Kini Y, Mehta H, Bhagyasree V. Sino-orbital mucormycosis in a COVID-19 patient: A case report. International Journal of Surgery Case Reports. 2021 May;82:105957.

8. Saldanha M, Reddy R, Vincent MJ. Title of the Article: Paranasal Mucormycosis in COVID-19 Patient. Indian J Otolaryngol Head Neck Surg [Internet]. 2021 Apr 22 [cited 2021 May 17]; Available from: https://link.springer.com/10.1007/s12070-021-02574-0

9. Revannavar SM, P S S, Samaga L, V K V. COVID-19 triggering mucormycosis in a susceptible patient: a new phenomenon in the developing world? BMJ Case Rep. 2021 Apr;14(4):e241663.

10. Moorthy A, Gaikwad R, Krishna S, Hegde R, Tripathi KK, Kale PG, et al. SARS-CoV-2, Uncontrolled Diabetes and Corticosteroids-An Unholy Trinity in Invasive Fungal Infections of the Maxillofacial Region? A Retrospective, Multi-centric Analysis. J Maxillofac Oral Surg [Internet]. 2021 Mar 6 [cited 2021 May 17]; Available from: http://link.springer.com/10.1007/s12663-021-01532-1

11. Werthman-Ehrenreich A. Mucormycosis with orbital compartment syndrome in a patient with COVID19. The American Journal of Emergency Medicine. 2021 Apr;42:264.e5-264.e8. 
12. Mekonnen ZK, Ashraf DC, Jankowski T, Grob SR, Vagefi MR, Kersten RC, et al. Acute Invasive Rhino-Orbital Mucormycosis in a Patient With COVID-19-Associated Acute Respiratory Distress Syndrome. Ophthalmic Plastic \& Reconstructive Surgery. 2021 Mar;37(2):e40-80.

13. Alekseyev K, Didenko L, Chaudhry B. Rhinocerebral Mucormycosis and COVID-19 Pneumonia. J Med Cases. 2021/01/19 ed. 2021 Mar;12(3):85-9.

14. Johnson AK, Ghazarian Z, Cendrowski KD, Persichino JG. Pulmonary aspergillosis and mucormycosis in a patient with COVID-19. Medical Mycology Case Reports. 2021 Jun;32:64-7.

15. Khatri A, Chang K-M, Berlinrut I, Wallach F. Mucormycosis after Coronavirus disease 2019 infection in a heart transplant recipient - Case report and review of literature. Journal of Medical Mycology. 2021 Jun;31(2):101125.

16. Dallalzadeh LO, Ozzello DJ, Liu CY, Kikkawa DO, Korn BS. Secondary infection with rhino-orbital cerebral mucormycosis associated with COVID-19. null. 2021 Mar 23;1-4.

17. Placik DA, Taylor WL, Wnuk NM. Bronchopleural fistula development in the setting of novel therapies for acute respiratory distress syndrome in SARS-CoV-2 pneumonia. Radiology Case Reports. 2020 Nov;15(11):2378-81.

18. Kanwar A, Jordan A, Olewiler S, Wehberg K, Cortes M, Jackson BR. A Fatal Case of Rhizopus azygosporus Pneumonia Following COVID-19. JoF. 2021 Feb 28;7(3):174.

19. Ahmadikia K, Hashemi SJ, Khodavaisy S, Getso MI, Alijani N, Badali H, et al. The doubleedged sword of systemic corticosteroid therapy in viral pneumonia: A case report and comparative review of influenza-associated mucormycosis versus COVID-19 associated mucormycosis. Mycoses. 2021 Feb $16 ; 10.1111 /$ myc. 13256 .

20. Veisi A, Bagheri A, Eshaghi M, Rikhtehgar MH, Rezaei Kanavi M, Farjad R. Rhino-orbital mucormycosis during steroid therapy in COVID-19 patients: A case report. European Journal of Ophthalmology. 2021 Apr 10;112067212110094.

21. Karimi-Galougahi M, Arastou S, Haseli S. Fulminant mucormycosis complicating coronavirus disease 2019 (COVID-19). Int Forum Allergy Rhinol. 2021 Mar 13;alr.22785.

22. Monte Junior ES do, Santos MEL dos, Ribeiro IB, Luz G de O, Baba ER, Hirsch BS, et al. Rare and Fatal Gastrointestinal Mucormycosis (Zygomycosis) in a COVID-19 Patient: A Case Report. Clin Endosc. 2020 Nov 30;53(6):746-9.

23. Waizel-Haiat S, Guerrero-Paz JA, Sanchez-Hurtado L, Calleja-Alarcon S, Romero-Gutierrez L. A Case of Fatal Rhino-Orbital Mucormycosis Associated With New Onset Diabetic Ketoacidosis and COVID-19. Cureus [Internet]. 2021 Feb 5 [cited 2021 May 17]; Available from: https://www.cureus.com/articles/51628a-case-of-fatal-rhino-orbital-mucormycosis-associated-with-new-onset-diabetic-ketoacidosis-and-covid-19

24. Pasero D, Sanna S, Liperi C, Piredda D, Branca GP, Casadio L, et al. A challenging complication following SARS-CoV-2 infection: a case of pulmonary mucormycosis. Infection [Internet]. 2020 Dec 17 [cited 2021 May 17]; Available from: http://link.springer.com/10.1007/s15010-020-01561-x

25. Zurl C, Hoenigl M, Schulz E, Hatzl S, Gorkiewicz G, Krause R, et al. Autopsy Proven Pulmonary Mucormycosis Due to Rhizopus microsporus in a Critically Ill COVID-19 Patient with Underlying Hematological Malignancy. JoF. 2021 Jan 27;7(2):88.

26. Black fungus has claimed 52 lives in maharashtra so far:Official. The Hindu [Internet]. 2021 May 14; Available from: https://www.thehindu.com/news/national/other-states/black-fungus-has-claimed-52-livesin-maharashtra-so-far-official/article34554570.ece 
27. India reports 8,848 mucormycosis cases, 23k more Amphotericin vials allocated. The times of India [Internet]. 2021 May 23; Available from: https://timesofindia.indiatimes.com/india/india-reports-8848mucormycosis-cases-23k-more-amphotericin-vials-allocated/articleshow/82855964.cms 